\title{
Analyst
}

\section{Label free colorimetric sensing of thiocyanate based on inducing aggregation of Tween 20-stabilized gold nanoparticles}

\author{
Zhiyang Zhang, ${ }^{a c}$ Jun Zhang, ${ }^{b}$ Chengli Qu, ${ }^{a}$ Dawei Pan, ${ }^{a}$ Zhaopeng Chen ${ }^{* a}$ and Lingxin Chen ${ }^{a}$ \\ Received 31st March 2012, Accepted 5th April 2012 \\ DOI: 10.1039/c2an35433k
}

\begin{abstract}
Based on inducing the aggregation of gold nanoparticles (AuNPs), a simple colorimetric method with high sensitivity and selectivity was developed for the sensing of thiocyanate $\left(\mathrm{SCN}^{-}\right)$in aqueous solutions. Citrate-capped AuNPs were prepared following a classic method and Tween 20 was subsequently added as a stabilizer. With the addition of $\mathrm{SCN}^{-}$, citrate ions on AuNPs surfaces were replaced due to the high affinity between $\mathrm{SCN}^{-}$and $\mathrm{Au}$. As a result, Tween 20 molecules adsorbed on the AuNPs surfaces were separated and the AuNPs aggregated. The process was accompanied by a visible color change from red to blue within $5 \mathrm{~min}$. The sensing of $\mathrm{SCN}^{-}$can therefore be easily achieved by a UV-vis spectrophotometer or even by the naked eye. The potential effects of relevant experimental conditions, including concentration of Tween $20, \mathrm{pH}$, incubation temperature and time, were evaluated to optimize the method. Under optimized conditions, this method yields excellent sensitivity ( $\mathrm{LOD}=0.2 \mu \mathrm{M}$ or $11.6 \mathrm{ppb}$ ) and selectivity toward $\mathrm{SCN}^{-}$. Our attempt may provide a costeffective, rapid and simple solution to the inspection of $\mathrm{SCN}^{-}$ions in saliva and environmental aqueous samples.
\end{abstract}

\section{Introduction}

As chemicals widely used in industries like fabric dyeing, electroplating baths and photographing, thiocyanates $\left(\mathrm{SCN}^{-}\right)$ pose a great threat to human health and the environment. ${ }^{1}$ It is known that $\mathrm{SCN}^{-}$can block the iodine uptake by the thyroid gland. ${ }^{2}$ Even worse $\mathrm{SCN}^{-}$in water may be converted to highly toxic chemical species, e.g. $\mathrm{CN}^{-}$and $\mathrm{CNCl}$ which are fatal to aquatic life. ${ }^{3}$ The concentration level of thiocyanate in saliva is also considered to be a good probe to distinguish between smokers and non-smokers. The thiocyanate concentrations in non-smokers' saliva have been found to be between 0.5 and $2 \mathrm{mM}$, while in smokers' saliva, concentrations of thiocyanate as high as $6 \mathrm{mM}$ have been found. ${ }^{4}$

Many methods, such as voltammetry, ${ }^{5}$ chromatography, ${ }^{6}$ potentiometry ${ }^{7}$ and fluorometry, ${ }^{1}$ have been developed for the determination of $\mathrm{SCN}^{-}$. However, most of them are timeconsuming or costly or require sophisticated instrumentation, which prevent them from being used for on-site analyses and field

${ }^{a}$ Key Laboratory of Coastal Zone Environmental Processes, Yantai Institute of Coastal Zone Research(YIC), Chinese Academy of Sciences(CAS), Shandong Provincial Key Laboratory of Coastal Zone Environmental Processes, YICCAS, Yantai Shandong 264003, P. R. China.E-mail: zhpchen@yic.ac.cn; Fax: +86 535 2109133; Tel: +86 535 2109133

${ }^{b}$ School of Tropical and Laboratory Medicine, Hainan Medical University, Haikou 571101, China

${ }^{c}$ Graduate University of Chinese Academy of Sciences, Beijing 100049, China tests. It is necessary to develop a simple, rapid, and sensitive method for the determination of $\mathrm{SCN}^{-}$.

Nanoparticles-based colorimetric assays have recently attracted growing attention due to their simplicity and sensitivity. As nano-materials that can be easily synthesized and functionalized, gold nanoparticles (AuNPs) have a high molar extinction coefficient and have often been used as base materials for the colorimetric sensing of various targets, e.g. proteins, ${ }^{8}$ cells, ${ }^{9}$ DNA $^{10}$ and metal ions, ${ }^{11}$ etc. Such sensors generally rely on the reaction between targets and ligands modified on the surfaces of the AuNPs. The formation of a target-ligand complex changes the distances between the AuNPs. Once the distances are less than the average diameter of the AuNPs, the color of the solutions changes from red to blue. Unfortunately, there is almost no selective ligand for anions which can be modified onto the AuNPs surface. The detection of anions cannot be achieved following the same strategy. The AuNPs-based selectively colorimetric assays of certain anions, normally, can be achieved by removal of the stabilizing agent from the AuNPs surface. For example, Liu and Tseng developed a colorimetric cyanide sensor using Polysorbate 40-stabilized AuNPs as the selective probe. Cyanide etched Polysorbate 40-stabilized AuNPs, result in the detachment of Polysorbate 40 from AuNPs, and therefore the AuNPs aggregated in $0.1 \mathrm{M} \mathrm{NaCl}$ solution due to the lack of stabilizer. ${ }^{12}$ Jung et al. described a colorimetric method for the sensing of iodide based on the high affinity between Au and $\mathrm{I}^{-}$. The addition of $\mathrm{I}^{-}$to adenosine triphosphate stabilized AuNPs leading to the aggregation of AuNPs since the adenosine 
triphosphate on the AuNPs was replaced by $\mathrm{I}^{-} \cdot{ }^{13} \mathrm{~A}$ similar strategy was also performed for the selective detection of thiolcontaining compounds. ${ }^{14}$

Recently, Pienpinijtham et al. developed a surface-enhanced Raman scattering method for the sensing of $\mathrm{SCN}^{-} .{ }^{15}$ The results showed that $\mathrm{SCN}^{-}$ions have a strong affinity for $\mathrm{Au}$. On the other hand, other research has indicated that Tween 20 could be strongly adsorbed on citrate-capped AuNPs surfaces and consequently stabilize the citrate-capped AuNPs against conditions of high ionic strength. The oxidization of citrate led to the departure of Tween 20 from the surfaces of the AuNPs, resulting in the aggregation of the AuNPs. ${ }^{16}$

Inspired by these two studies, we presume that citrate can be replaced by $\mathrm{SCN}^{-}$, as a result, leading to the removal of Tween 20 from the surface of the AuNPs, and thus resulting in the aggregation of Tween 20-stabilized AuNPs. Herein, we describe a sensitive and selective colorimetric strategy using Tween 20-stabilized AuNPs for the sensing of $\mathrm{SCN}^{-}$.

\section{Experimental}

\section{Chemicals and apparatus}

Hydrogen tetrachloroaurate(III) dehydrate $\left(\mathrm{HAuCl}_{4}\right)$, trisodium citrate, $\mathrm{Na}_{2} \mathrm{HPO}_{4}, \quad \mathrm{NaH}_{2} \mathrm{PO}_{4}, \mathrm{Na}_{2} \mathrm{SO}_{4}, \mathrm{NaNO}_{3}, \mathrm{Na}_{2} \mathrm{CO}_{3}$, $\mathrm{NaNO}_{2}, \mathrm{NaClO}_{4}, \mathrm{NaCl}, \mathrm{MgCl}_{2}, \mathrm{AlCl}_{3}, \mathrm{CrCl}_{3}, \mathrm{MnCl}_{2}, \mathrm{CuCl}_{2}$, $\mathrm{Pb}\left(\mathrm{NO}_{3}\right)_{2}, \mathrm{ZnCl}_{2}$, Tween 20, Tween 40, Tween 60, Tween 80, ethylene diamine tetraacetic acid (EDTA) and KSCN were obtained from Sinopharm Chemical Reagent (China). Cyanide standard solution $\left(50 \mathrm{mg} \mathrm{L}^{-1}\right.$ ) was purchased from Shanghai Institute of Measurement and Testing Technology. All other chemicals were analytical reagent grade or better. Solutions were prepared with deionized water (18.2 $\mathrm{M} \Omega \mathrm{cm}$ specific resistance) obtained from a Pall Cascada ${ }^{\circledR}$ laboratory water system.

Transmission electron microscopy (TEM) analyses were performed on a JEM-1230 electron microscope (Japan) operating at $100 \mathrm{kV}$. Absorption spectra were measured on a Beckman Coulter DU-800 UV/visible spectrophotometer (USA). Dynamic light scattering (DLS) experiments were performed on a Zeta Potential/Particle Sizer (Nicomp ${ }^{\circledR} 380$ ZLS, USA).

\section{Synthesis of the AuNPs}

AuNPs $(\Phi \approx 13 \mathrm{~nm})$ colloids were synthesized according to the literature method. ${ }^{17}$ Briefly, $2 \mathrm{~mL}$ of $50 \mathrm{mM} \mathrm{HAuCl} 4$ was added to a two-neck flask containing $98 \mathrm{~mL}$ of deionized water. The solution was stirred and refluxed vigorously. Then $10 \mathrm{~mL}$ of $38.8 \mathrm{mM}$ sodium citrate was quickly added. The reflux was continued for another $20 \mathrm{~min}$ after the solution color had changed from pale yellow to deep red. The solution was finally cooled to room temperature under stirring. The particle concentration of the gold nanoparticles ( $c a .15 \mathrm{nM}$ ) was determined according to Beer's law using an extinction coefficient of ca. $2.43 \times 10^{8} \mathrm{M}^{-1} \mathrm{~cm}^{-1}$ at $520 \mathrm{~nm} .{ }^{18}$

\section{Assay procedures}

Tween 20-stabilized AuNPs (Tween 20-AuNPs) were prepared by adding $10 \mu \mathrm{L}$ Tween 20 at different concentrations to $1.0 \mathrm{~mL}$ AuNPs. The solution was incubated at room temperature for
$10 \mathrm{~min}$. For the sensing of $\mathrm{SCN}^{-}, 100 \mu \mathrm{L}$ Tween 20-AuNPs was added to $910 \mu \mathrm{L}$ PBS solution ( $\mathrm{pH} 7.3,0.2 \mathrm{M}$ ) containing different concentrations of $\mathrm{SCN}^{-}$and $1.0 \mathrm{mM}$ EDTA (used as a masking reagent to eliminate the affect of $\mathrm{Hg}^{2+}$ ). After incubation at different temperatures for different time, the absorption spectra of the resulting solutions were record.

\section{Analysis of real samples}

Environmental aqueous samples: a series of samples were prepared by spiking standard solutions of $\mathrm{SCN}^{-}$to local tap water. $\mathrm{Na}_{2} \mathrm{HPO}_{4}$ and $\mathrm{NaH}_{2} \mathrm{PO}_{4}$ were added to these spiked samples to adjust the $\mathrm{pH}$ to 7.3. Thereafter Tween 20-AuNPs $(100 \mu \mathrm{L})$ were added to $910 \mu \mathrm{L}$ of the above samples. The final solutions were incubated at $45^{\circ} \mathrm{C}$ for $5 \mathrm{~min}$ before the spectra were recorded.

Saliva samples: five smokers and five non-smokers' saliva were collected. To $1.0 \mathrm{~mL}$ of these samples, $200 \mu \mathrm{L}$ trichloroacetic acid $(10 \%, \mathrm{v} / \mathrm{v})$ was added. The samples were incubated at $4{ }^{\circ} \mathrm{C}$ for $15 \mathrm{~min}$ before centrifugation to remove protein. The $\mathrm{SCN}^{-}$ concentration in saliva was determined by a classical method using $\mathrm{Fe}^{3+}$ as a color producing reagent. For sensing $\mathrm{SCN}^{-}$in saliva by the proposed method, $6 \mu \mathrm{L}$ saliva (diluted 5 folds) was added to $1 \mathrm{~mL}$ PBS solution containing $100 \mu \mathrm{L}$ Tween 20-stabilized AuNPs. The color change was recorded by a digital camera.

\section{Results and discussion}

\section{Mechanism of the sensor}

As shown in Scheme 1, AuNPs were first stabilized by Tween 20, a nonionic surfactant. Tween 20 coating has been found to shield the citrate adsorbed on the Au surface, which ensured that AuNPs were very stable in high ionic strength solution. ${ }^{16}$ The Tween 20-AuNPs appeared wine red in 0.2 M PBS solution ( $\mathrm{pH}$ 7.3) before the addition of $\mathrm{SCN}^{-}$. In the presence of $\mathrm{SCN}^{-}$, the Tween 20-AuNPs tended to aggregate along with a color change from red to blue owing to the fact that the citrate on the AuNPs was replaced by $\mathrm{SCN}^{-}$. The affinity between $\mathrm{SCN}^{-}$and $\mathrm{Au}$ is very strong with a high stability constant $\left(\lg \beta_{4}\right)$ of $c a .42 .{ }^{19}$ It is reported that $-\mathrm{SCN}$ is similar to $-\mathrm{SH}$ which can bind strongly onto the surface of AuNPs. The replacement lead to the departure of Tween 20 from the surfaces of the AuNPs, resulting in the

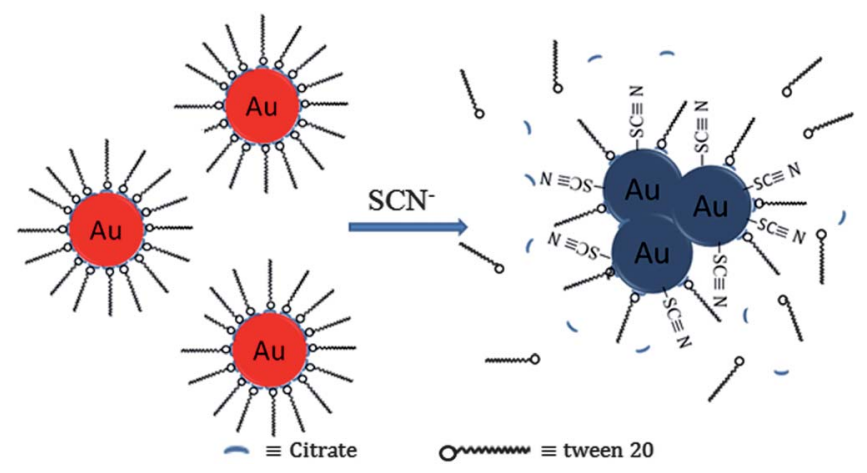

Scheme 1 Mechanism of Tween 20-AuNPs for sensing of $\mathrm{SCN}^{-}$. 
aggregation of Tween 20-AuNPs because of the lack of a stabilizing agent.

To confirm that these AuNPs aggregated, we compared the UV-vis absorption spectra and the DLS data of Tween 20-AuNPs before and after incubation with $\mathrm{SCN}^{-}$. As shown in Fig. 1, the Tween 20-AuNPs appears wine red with a typical peak around $525 \mathrm{~nm}$ (photographic image A and curve a). The phenomenon was reported to result from the surface plasmon resonance having an extremely high extinction coefficient. Once the AuNPs aggregated, a red shift of the surface plasmon absorption occurs and is accompanied by a visible colour change from red to blue. This is exactly what was observed in this study, wherein the addition of $\mathrm{SCN}^{-}$caused the maximum absorption wavelength to shift from 525 to around $650 \mathrm{~nm}$ and a color change to occur from red to blue (photographic image B and curve b).

Further evidence can be obtained by comparing the difference in the DLS data. The DLS data of Tween 20-AuNPs before and after incubation with $\mathrm{SCN}^{-}$are shown in Fig. 2. The intensityweighted Gaussian distribution curves show that the average hydrodynamic diameter of well dispersed Tween 20-AuNPs was $48.5 \mathrm{~nm}$, while that of the $\mathrm{SCN}^{-}$-induced aggregated AuNPs increased to $112.9 \mathrm{~nm}$ (Fig. 2). It is reasonable to conclude that the aggregation of AuNPs should be attributed to the addition of $\mathrm{SCN}^{-}$.

\section{Optimization of the sensing system}

It is well known that the chain length of the surfactant has a great effect on the stability of the AuNPs and therefore affects the sensitivity of the proposed method. The effect of the chain length of the surfactant was investigated. Tween 20-, 40-, 60- and 80-stabilized AuNPs were used as a color producing-reagent to probe $\mathrm{SCN}^{-}$with a concentration of $1.0 \mu \mathrm{M}$ in PBS solution. Only the color of Tween 20-AuNPs changed from wine red to blue, showing that AuNPs stabilized by surfactant with a longer chain length are more stable than those stabilized by a surfactant with a shorter chain length. The results were also consistent with

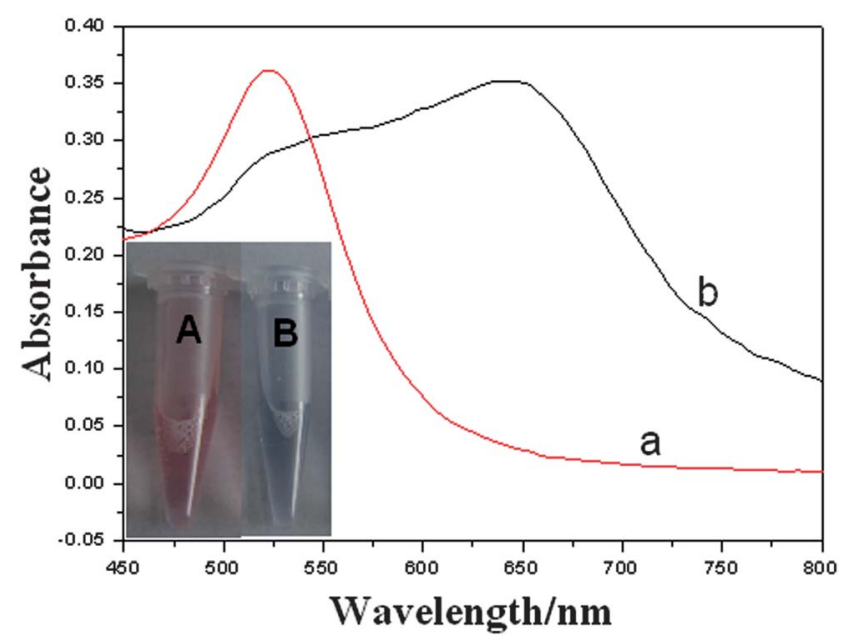

Fig. 1 Absorption spectra and color (inset) of Tween 20-AuNPs in $0.2 \mathrm{M}$ PBS (pH 7.3) in the absence (a, A) and presence (b, B) of $\mathrm{SCN}^{-}$ $(1.0 \mu \mathrm{M})$.

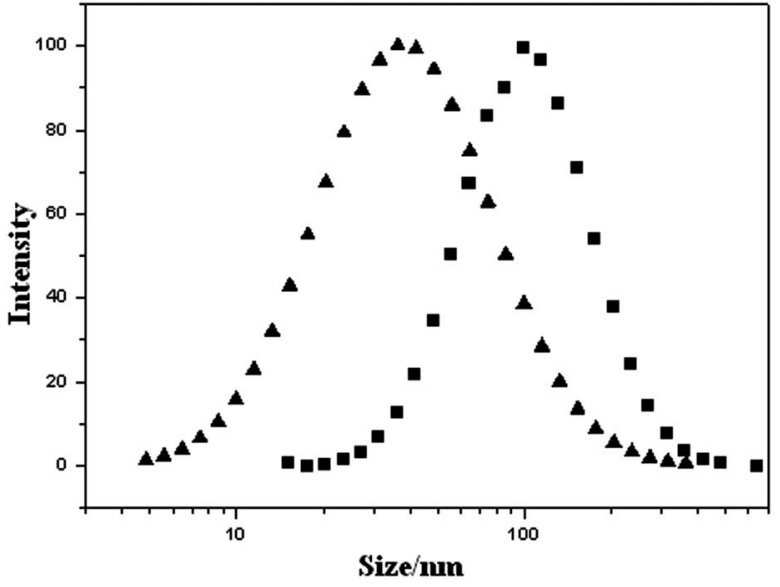

Fig. 2 DLS measurement for Tween 20-AuNPs ( $\boldsymbol{\Delta})$ before and ( $\boldsymbol{\square})$ after incubation with $1.0 \mu \mathrm{M} \mathrm{SCN}^{-}$.

those reported by Liu and Tseng $\left(\mathrm{SCN}^{-}\right.$could not induce Tween 40-stabilized AuNPs aggregation ${ }^{12}$ ). So Tween 20 was selected as a stabilizer in this study.

With respect to the absorption spectra shown in Fig. 1, the ratio of the extinction values at $650 \mathrm{~nm}$ to those at $525 \mathrm{~nm}$ $\left(A_{650 \mathrm{~nm}} / A_{525} \mathrm{~nm}\right)$ was chosen as the criteria for optimization. Factors like $\mathrm{pH}$, concentrations of stabilizing agent, incubation temperature and time were further evaluated.

Fig. 3(A) shows the effect of $\mathrm{pH}$ on the ratio of $A_{650 \mathrm{~nm}} /$ $A_{525} \mathrm{~nm}$. One can see that the ratio of $A_{650 \mathrm{~nm}} / A_{525} \mathrm{~nm}$ first increased gradually with an increase in $\mathrm{pH}$ from 5.8 to 7.3, and then decreased rapidly when the $\mathrm{pH}$ exceeded 7.7. We reasoned that the $\mathrm{pH}$ influenced the affinity between $\mathrm{SCN}^{-}$and $\mathrm{Au}$, and that a strongly alkaline condition was adverse to our analytical system. The maximum $A_{650 \mathrm{~nm}} / A_{525} \mathrm{~nm}$ appeared to be approximately 7.3 , thus a $\mathrm{pH}$ of 7.3 was selected in subsequent experiments.

Fig. 3(B) describes the effect of incubation temperature on the ratio of $A_{650 \mathrm{~nm}} / A_{525 \mathrm{~nm}}$. Obviously, the ratio of $A_{650 \mathrm{~nm}} / A_{525 \mathrm{~nm}}$ was enhanced by an increase in incubation temperature within
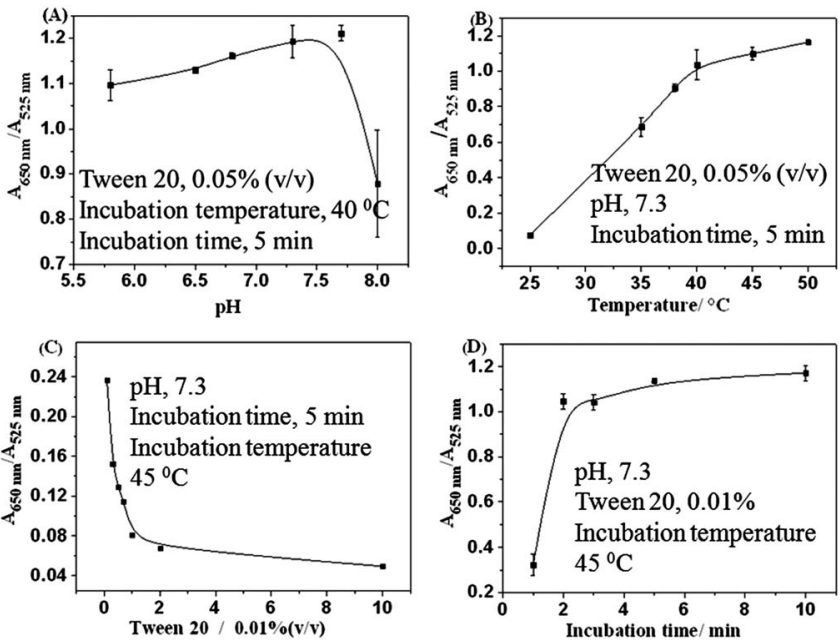

Fig. 3 Effects of (A) $\mathrm{pH}$, (B) incubation temperature, (C) concentration of Tween and (D) incubation time on the ratio of of $A_{650 \mathrm{~nm}} / A_{525} \mathrm{~nm}$, respectively. The concentration of $\mathrm{SCN}^{-}$used in $\mathrm{A}, \mathrm{B}$ and $\mathrm{D}$ was $1.0 \mu \mathrm{M}$. 
the range of 25 to $45^{\circ} \mathrm{C}$. When the temperature reached $40^{\circ} \mathrm{C}$, the ratio tended to reach a plateau. This is because a high temperature improved the diffusion rate of $\mathrm{SCN}^{-}$and Tween 20-AuNPs and, consequently, increased the collision rate between Tween 20 -AuNPs and $\mathrm{SCN}^{-}$. To obtain high sensitivity and low detection deviation, an incubation temperature of $45^{\circ} \mathrm{C}$ was selected in the subsequent experiments.

It should be noted that Tween 20 played an important role in this study. Generally, AuNPs are more stable as more Tween 20 is added, resulting in a low background signal. However, excessive Tween 20 obstructs the replacement of citrate by $\mathrm{SCN}^{-}$and reduces the sensitivity. So an appropriate Tween 20 concentration needed to be investigated. Fig. 3(C) displays the effect of Tween 20 on the ratio of $A_{650} \mathrm{~nm} / A_{525} \mathrm{~nm}$ in the absence of $\mathrm{SCN}^{-}$. The ratio of $A_{650 \mathrm{~nm}} / A_{525} \mathrm{~nm}$ first declined sharply with an increase in the concentration of Tween 20 from 0 to $0.01 \%$ (v/v), indicating that the stability of the AuNPs increased with an increase in the concentration of Tween 20. When the concentration of Tween 20 exceeded $0.01 \%(\mathrm{v} / \mathrm{v})$, the ratio of $A_{650 \mathrm{~nm}} / A_{525} \mathrm{~nm}$ tended to stabilize, showing that the AuNPs were relatively stable under these conditions. Finally, taking these two factors into consideration, we selected a Tween 20 concentration of $0.01 \%(\mathrm{v} / \mathrm{v})$ in subsequent experiments.

Under the optimized conditions mentioned above, we tested the effect of incubation time on the ratio of $A_{650 \mathrm{~nm}} / A_{525 \mathrm{~nm}}$ from $1 \mathrm{~min}$ to $10 \mathrm{~min}$. As shown in Fig. 3(D), the ratio of $A_{650 \mathrm{~nm}} / A_{525 \mathrm{~nm}}$ first increased rapidly with an increase in the incubation time (0-2 min) and then varied slightly. Hence, all subsequent tests were carried out with an incubation time of $5 \mathrm{~min}$.

\section{Sensitivity}

Under optimum conditions ( $\mathrm{pH}, 7.3$; incubation temperature, $45{ }^{\circ} \mathrm{C}$; Tween $20,0.01 \%(\mathrm{v} / \mathrm{v})$; incubation time, $\left.5 \mathrm{~min}\right)$, we evaluated the sensitivity of this probe towards $\mathrm{SCN}^{-}$. When the concentrations of $\mathrm{SCN}^{-}$varied from 0 to $2.0 \mu \mathrm{M}$, the absorption peak at $525 \mathrm{~nm}$ decreased while that at $650 \mathrm{~nm}$ increased (Fig. 4B), along with a gradual color change from red to blue

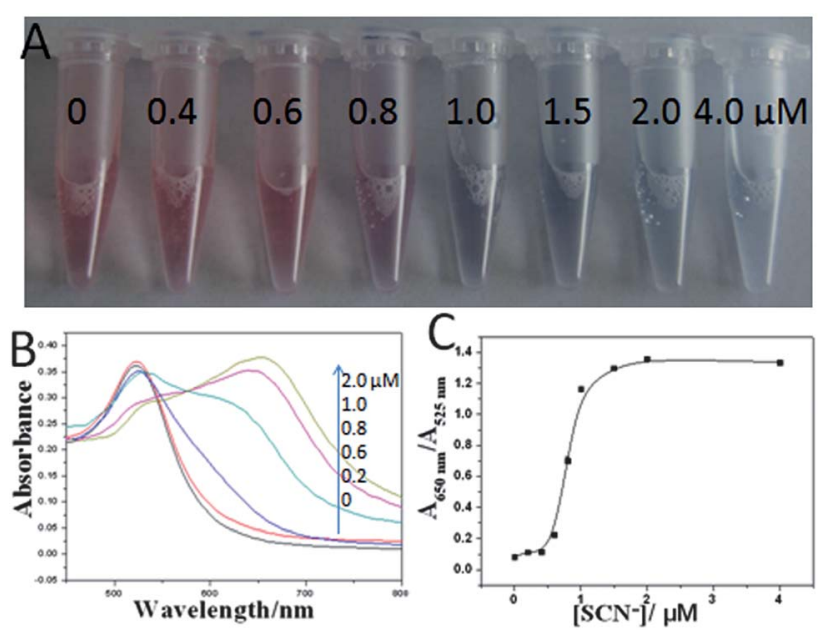

Fig. 4 Color (A), absorption spectra (B) and the ratio of $A_{650 \mathrm{~nm}} / A_{525} \mathrm{~nm}$ (C) after incubation of Tween 20-AuNPs with different concentrations of $\mathrm{SCN}^{-}$. Conditions: $\mathrm{pH}$ 7.3; Tween 20, 0.01\% (v/v); incubation temperature $45^{\circ} \mathrm{C}$; incubation time, $5 \mathrm{~min}$.
(Fig. 4A). It should be noted that $0.8 \mu \mathrm{M} \mathrm{SCN}^{-}$would induce an obvious color change, which indicated that this low concentration of $\mathrm{SCN}^{-}$could be detected by the naked eye. Fig. $4 \mathrm{C}$ showed that the ratio of $A_{650 \mathrm{~nm}} / A_{525} \mathrm{~nm}$ increased with an increase in $\mathrm{SCN}^{-}$concentration over the range of 0.2 to $2.0 \mu \mathrm{M}$. A further increase in the concentration of $\mathrm{SCN}^{-}$caused no obvious $A_{650 \mathrm{~nm}} / A_{525 \mathrm{~nm}}$ value change, indicating that the saturation point had been reached. Additionally, the detectable concentration of this assay was as low as $0.2 \mu \mathrm{M}$. Although the sensitivity of the proposed method is relatively lower than some other nanomaterial-based sensors, such as a surface-enhanced Raman scattering method using starch-reduced gold nanoparticles ${ }^{15}$ and the use of an electrochemical sensor based on a nano-silver coated multi-walled carbon nanotubes modified glassy carbon electrode, ${ }^{20}$ it has no demands of special instrumentation and thereby is more practical for on-site tests.

\section{Selectivity}

To evaluate whether this response is selective toward $\mathrm{SCN}^{-}$, the influence of other common ions was investigated. As shown in the inset of Fig. 5, among the tested ions, $\mathrm{SCN}^{-}$and $\mathrm{CN}^{-}$caused an obvious color change. Fig. 5 showed the responses of Tween 20-AuNPs to $1.0 \mu \mathrm{M}$ of $\mathrm{SCN}^{-}, \mathrm{CN}^{-}, \mathrm{S}^{2-}, 10 \mu \mathrm{M} \mathrm{Ag}^{+}, \mathrm{Hg}^{2+}$ and $100 \mu \mathrm{M}$ of other individual ions. $\mathrm{SCN}^{-}$and $\mathrm{CN}^{-}$were found to greatly increase the ratio of $A_{650 \mathrm{~nm}} / A_{525} \mathrm{~nm}$. Other ions could not affect the ratio of $A_{650 \mathrm{~nm}} / A_{525 \mathrm{~nm}}$ and the solution color. The interference of cyanide is not a fatal defect to our proposed method. First, each analytical method has its own applicable samples and targets. For example, our method is applicable to the inspection of $\mathrm{SCN}^{-}$in saliva. Second, $\mathrm{CN}^{-}$occurs rarely in nature and was barely detected in most samples. In comparison, thiocyanates have been widely used in industries like fabric dyeing, electroplating baths, photographing etc. The interference of $\mathrm{CN}^{-}$, in other words, may be another noteworthy point of our method.

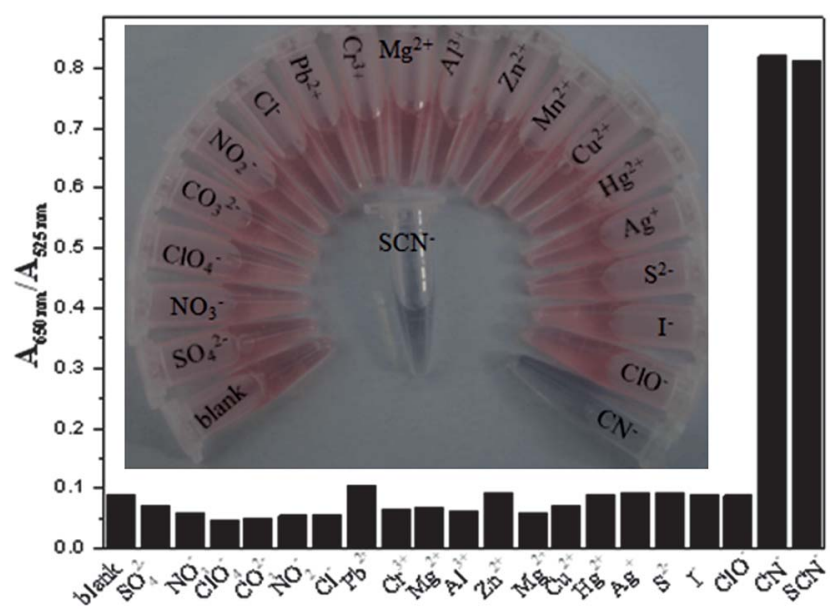

Fig. 5 The colors (inset) and ratio of $A_{650 \mathrm{~nm}} / A_{525} \mathrm{~nm}$ responses to common ions at $100 \mu \mathrm{M}$ (besides $\mathrm{SCN}^{-} 1.0 \mu \mathrm{M}, \mathrm{S}^{2-} 1.0 \mu \mathrm{M}, \mathrm{CN}^{-} 1.0 \mu \mathrm{M}$, $\left.\mathrm{Ag}^{+} 10 \mu \mathrm{M}, \mathrm{Hg}^{2+} 10 \mu \mathrm{M}\right)$. Experimental conditions: $\mathrm{pH}$ 7.3; Tween 20, $0.01 \%(\mathrm{v} / \mathrm{v})$, EDTA $1.0 \mathrm{mM}$, incubation temperature, $45^{\circ} \mathrm{C}$; incubation time, 5 min. 


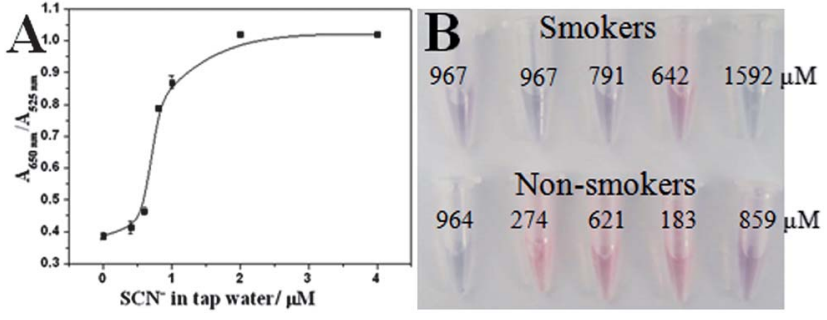

Fig. 6 Tween 20-AuNPs responses to different concentration of $\mathrm{SCN}^{-}$ in tap water (A) and digital photo of the proposed method for sensing of five smokers' and five non-smokers' saliva (B).

\section{Application in analysis of saliva and tap water samples}

To investigate the application of the proposed approach, we applied the method to the determination of $\mathrm{SCN}^{-}$in saliva and tap water samples. As shown in Fig. 6A, the value of $A_{650} \mathrm{~nm} / A_{525} \mathrm{~nm}$ increased with an increase in the spiked concentration of $\mathrm{SCN}^{-}$in tap water over the range of 0.4 to 2.0 $\mu \mathrm{M}$, which is similar to the phenomenon mentioned above. The lowest detectable concentration of $\mathrm{SCN}^{-}$in tap water was about $0.4 \mu \mathrm{M}$. Fig. 6B is the digital photo of the proposed method for sensing five smokers' and five non-smokers' saliva. The labels on the centrifuge tubes are the original concentration of $\mathrm{SCN}^{-}$in saliva determined by the classic method. It should be noted here that the color changes were the response to the samples after dilution 1000 fold. Obviously, the color of Tween 20-AuNPs would change from red to blue when $\mathrm{SCN}^{-}$in saliva exceeded $0.7 \mathrm{mM}$. The results also show that the level of $\mathrm{SCN}^{-}$in smokers' saliva is higher than that in non-smokers' saliva. These results indicate that the method can be applied to the inspection of $\mathrm{SCN}^{-}$in real samples, such as tap water and saliva.

\section{Conclusions}

This study presents a sensitive and selective method for the determination of thiocyanate in aqueous solutions. Compared to traditional methods, the proposed method was characterized by its simplicity and rapidity. First, no complicated sample pretreatment like separation or preconcentration was needed. Second, the obvious color change induced by thiocyanate can be easily observed by the naked eye, suggesting excellent applicability to field tests. This method may offer a new cost-effective, rapid and simple solution to the inspection of $\mathrm{SCN}^{-}$ion in saliva and environmental aqueous samples.

\section{Acknowledgements}

The research was financially supported by the Department of Science and Technology of Shandong Province (BS2009DX006,
2008GG20005005), NSFC (no. 20975089, 21007087), CAS (KZCX2-YW-JS208) and the 100 Talents Program of the CAS.

\section{Notes and references}

1 Y. Zhang, H. Wang and R. H. Yang, Sensors, 2007, 7, 410-419.

2 P. A. Dahlberg, A. Bergmark, M. Eltom, L. Bjorck and O. Claesson, Am. J. Clin. Nutr., 1985, 41, 1010; J. K. Miller, B. R. Moss, E. W. Swanson and W. A. Lyke, J. Dairy Sci., 1975, 58, 526.

3 R. M. Naik, B. Kumar and A. Asthana, Spectrochim. Acta, Part A, $2010,75,1152$.

4 T. F. Maliszewski and D. E. Bass, J. Appl. Physiol., 1955, 8, 289291.

5 J. A. Cox, T. Gray and K. R. Kulkarni, Anal. Chem., 1988, 60, 1710; R. Bilewicz and Z. Kublik, Anal. Chim. Acta, 1981, 123, 201; K. S. Parubochaya, V. V. Pnev and M. S. Zakharov, J. Anal. Chem., 1978, 33, 1382.

6 J. Li, Y. Wang and L. Liang, Chin. J. Chromatogr., 2010, 28, 422; I. Demkowska, Z. Polkowska and J. Namiesnik, J. Chromatogr., B: Anal. Technol. Biomed. Life Sci., 2008, 875, 419; E. Saussereau, J.-P. Goulle and C. Lacroix, J. Anal. Toxicol., 2007, 31, 383.

7 M. M. Ardakani, M. Jamshidpour, H. Naeimi and L. Moradi, Anal. Sci., 2006, 22, 1221; M. M. Ardakani, M. A. Karimi, R. Mazidi, H. Naeimi and K. Rabiei, Can. J. Anal. Sci. Spectrosc, 2007, 52, 233; P. Buhlmann, L. Yahya and R. Enderes, Electroanalysis, 2004, 16, 973; T. Korenaga, Mikrochim. Acta, 1979, 2, 455.

8 Y.-Y. Chen, C.-W. Tseng, H.-Y. Chang, Y.-L. Hung and C.-C. Huang, Biosens. Bioelectron., 2011, 26, 3160; C. S. Tsai, T. B. Yu and C. T. Chen, Chem. Commun., 2005, 4273; H. Wei, B. Li, J. Li, E. Wang and S. Dong, Chem. Commun., 2007, 3735.

9 W. Lu, R. Arumugam, D. Senapati, A. K. Singh, T. Arbneshi, S. A. Khan, H. Yu and P. C. Ray, ACS Nano, 2010, 4, 1739; C. D. Medley, J. E. Smith, Z. Tang, Y. Wu, S. Bamrungsap and W. Tan, Anal. Chem., 2008, 80, 1067.

10 M. S. Han, A. K. R. Lytton-Jean, B. K. Oh, J. Heo and C. A. Mirkin, Angew. Chem., Int. Ed., 2006, 45, 1807; S. J. Hurst, M. S. Han, A. K. R. Lytton-Jean and C. A. Mirkin, Anal. Chem., 2007, 79, 7201.

11 Y. Wang, F. Yang and X. Yang, Biosens. Bioelectron., 2010, 25, 1994; G. Wang, Y. Wang, L. Chen and J. Choo, Biosens. Bioelectron., 2010, 25, 1859 .

12 C. Y. Liu and W. L. Tseng, Chem. Commun., 2011, 47, 25502552.

13 E. Jung, S. Kim, Y. Kim, S. H. Seo, S. S. Lee, M. S. Han and S. Lee, Angew. Chem., Int. Ed., 2011, 50, 4386-4389.

14 J. H. Lin, C. W. Chang, Z. H. Wu and W. L. Tseng, Anal. Chem., 2010, 82, 8775-8779; M. H. Kim, S. S. Lee, S. J. Chung, H. H. Jang, S. Yi, S. Kim, S. K. Chang and M. S. Han, Tetrahedron Lett., 2010, 51, 2228-2231; Z. Chen, S. Luo, C. Liu and Q. Cai, Anal. Bioanal. Chem., 2009, 395, 489-494.

15 P. Pienpinijtham, X. X. Han, S. Ekgasit and Y. Ozaki, Anal. Chem., $2011, \mathbf{8 3}, 3655$.

16 C.-Y. Lin, C.-J. Yu, Y.-H. Lin and W.-L. Tseng, Anal. Chem., 2010, 82, 6830 .

17 G. Frens, Nature, Phys. Sci., 1973, 241, 20.

18 R. C. Jin, G. S. Wu, Z. Li, C. A. Mirkin and G. C. Schatz, J. Am. Chem. Soc., 2003, 125, 1643-1654.

19 A. Dawson and P. V. Kamat, J. Phys. Chem. B, 2000, 104, 11842; K. G. Thomas, J. Zajicek and P. V. Kamat, Langmuir, 2002, 18, 3722.

20 P. Yang, W. Wei and C. Tao, Anal. Chim. Acta, 2007, 585, 331336. 